\title{
Immunisation state and its documentation in hospital patients
}

\author{
M J Ferson
}

\begin{abstract}
Two prospective surveys of the immunisation state and its documentation were conducted among children under 2 years old attending a children's hospital. A survey of 111 children attending the casualty or outpatient departments showed that, according to reliable records, $106(95 \%)$ were fully immunised for age with oral polio vaccine, $93(84 \%)$ with triple antigen, and 26 of 33 children $\geqslant 16$ months of age (79\%) with measles-mumps vaccine. A survey of 204 inpatients showed that, according to verified records, significantly fewer inpatients than outpatients were fully immunised for age with oral polio vaccine $(176,86 \%)$ and with triple antigen $(144$, $71 \%)$. The proportion of inpatients vaccinated with measles-mumps vaccine was $81 \%$ (48 of 59). The inpatient figures are all lower than the $95 \%$ goal of current child immunisation programmes. Although parents of $98 \%$ of inpatients had a personal health record for the child, it was available at the time of admission for less than half the children. Lack of use of the personal health record by admitting medical staff was reflected in incorrect or absent documentation of the immunisation state in 17 of $49(35 \%)$ of the records of children verified to have inadequate immunisations. Parents and health care staff need to be educated in the optimal use of the personal health record. Hospital paediatric staff need to be encouraged to verify the immunisation state of all young children, on admission, and arrange to rectify any deficiency found.
\end{abstract}

The key to a successful immunisation programme lies in ensuring a high degree of compliance in children of preschool age. During the first two years of life, the child immunisation schedule recommended in New South Wales specifies that triple antigen and Sabin oral polio vaccine should be given at 2,4 , and 6 months of age, measles-mumps vaccine at 15 months of age, and a booster of triple antigen at 18 months of age. ${ }^{1}$ From July 1989 measles-mumps vaccine was replaced by measles-mumps-rubella vaccine. ${ }^{2}$ In the United States, where school aged children are reported to have a compliance of greater than $95 \%$ with routine immunisation, ${ }^{3}$ appreciable numbers of cases of measles $^{4} 5$ and mumps ${ }^{6}$ do still occur in children below school age. Many of the cases described in these reports were in children over 16 months of age who had missed being vaccinated against measles and mumps. To prevent this happening, those providing health care need to use all opportunities to ensure that their patients are appropriately immunised. ${ }^{7-9}$ Paediatric authorities in both Great Britain ${ }^{10}$ and the United States ${ }^{11}$ have therefore strongly recommended that every hospital admission should be used as an opportunity to determine the child's immunisation state, and to correct any deficiency found.

This presupposes that each child's immunisation state is known by parent or provider, or both. The retrieval of this information accurately, however, is not without its difficulties. Parental recall is fallible, ${ }^{12}$ so that a form of documentation is required that is acceptable to, and will be used appropriately by, both parents and health providers. Partly to solve this problem, the personal health record booklet was designed by the New South Wales Department of Health in conjunction with the Royal Australian College of General Practitioners as a health record to be held by parents. Since the beginning of 1988 mothers who have given birth in obstetric units in New South Wales and the Australian Capital Territory have received a personal health record in which their child's immunisations and other information about health should be recorded. ${ }^{13}$ So far the value of the personal health record as an immunisation record does not seem to have been measured.

In response to calls to examine admission to hospital as an opportunity to improve immunisation uptake in young children, and prompted by the need to evaluate the personal health record as a method of recording immunisations, we conducted a prospective study among children under the age of 2 years who were attending the Prince of Wales Children's Hospital. The choice of this age group reflected concerns about compliance with the primary course of vaccination with triple antigen, oral polio vaccine, and measles-mumps and with the 18 month booster, and follows recommendations of the World Health Organisation for the assessment of compliance with immunisation. ${ }^{14}$ The specific aims of the study were (i) to determine compliance with routine chidhood immunisation of a hospital based population sample; (ii) to assess the extent of use of the personal health record as the record of immunisations held by parents; and (iii) to examine the accuracy, and thus the value, of the immunisation history of each inpatient as it was recorded in the medical notes.

Subjects and methods CASUALTY AND OUTPATIENT SURVEY

Parents of children aged from 3 to 25 months who were attending the children's outpatients 
department or the paediatric casualty department were asked to complete a brief questionnaire in which they were asked to give the child's sex, date of birth, and the suburb where they lived. Other details requested concerned routine immunisations in the first two years of life-that is, number of doses of triple antigen, combined diphtheria-tetanus, and oral polio vaccine given in the first year, whether measlesmumps or measles-mumps-rubella vaccine was received, whether the 18 month booster was received, and if so, whether it was triple antigen or combined diphtheria-tetanus. A contact telephone number was sought, and an attempt was made later to contact all parents of children for whom a Sydney telephone number was recorded. The interviewer then asked the parents to verify the responses to the survey by referring to any immunisation records held at home. In some cases, parents asked the interviewer to contact the provider of the immunisation for validation.

\section{INPATIENT SURVEY}

The survey questionnaire was given to mothers of children aged between 3 and 25 months who were inpatients of the Prince of Wales Children's Hospital during the last six months of 1989. Those with haematological or oncological disorders were excluded. In addition to the questions included in the outpatient survey, the interviewer asked the source(s) of the child's immunisations, and whether the parents held a personal health record or other immunisation record for the child. The interviewer then asked to see the child's personal health record. If it could not be seen during that admission, permission was sought to either contact the parents later or telephone the immunisation provider(s) to verify the information about immunisations that had been provided by the mother. Finally, the hospital record was examined to see whether the child had been admitted urgently or electively and how accurately the immunisations had been recorded by admitting medical staff. For each inpatient, the medical record of immunisations was compared with the records held by parents or providers and classified as: (a) correct-detailed (numbers and types of doses recorded fully and correctly), (b) correctabbreviated (intelligible and correct, but medical paraphrasing used or ages but not types of vaccine recorded), (c) incorrect, and (d) undocumented (immunisations either not mentioned, or in so shortened a form as to be meaningless).

\section{ANALYTICAL METHODS}

For the purposes of analysis, children were considered to have incomplete immunisations for age if they had not received a scheduled dose at the time of the survey, and it was more than one month overdue. ${ }^{15}$ For example, children were held to have missed measles-mumps vaccination if they were at least 16 months of age at the time of the survey, and to have missed the 18 month booster if they were at least 19 months of age. Statistical comparisons between groups were made with the $\chi^{2}$ test, with the Yates's correction for continuity when required.

\section{Results}

CASUALTY AND OUTPATIENT SURVEY

Of 154 survey forms on which a Sydney telephone number had been recorded, it was possible to contact the parents of 111 children. Of the remainder, 30 children $(19 \%)$ were no longer living at the address given, or the telephone number was unobtainable, and the parents of eight children kept no records and could not name the providers; parents of five were uncooperative. Verified data were available for all 111 children. There were 48 (43\%) girls and 63 boys, mean age $11 \cdot 2$ months. Based on documented immunisation data, 101 (9\%) had received all required first year doses of triple antigen, and of 21 children old enough to have also received the 18 month booster injection, 13 had received this dose as triple antigen, and two as combined diphtheria-tetanus vaccine. In accordance with the recommended schedule (which specifies four doses of triple antigen in the first two years) 93 (84\%) of the 111 children were appropriately immunised for age with triple antigen, and a further seven $(6 \%)$ had received some doses as combined diphtheria-tetanus. One hundred and six children $(95 \%)$ had received the correct number of doses of oral polio vaccine for age, and $26(79 \%)$ of the 33 children aged 16 months or older had been vaccinated with measles-mumps/measlesmumps-rubella.

When verified data were compared with the information initially recorded on the survey form, 106 children were documented to have been given three injections (triple antigen/ combined diphtheria-tetanus, or both) in the first year, but this had been initially recalled in only 95 children. This difference between verified and recalled data is significant $\left(\chi^{2}=5 \cdot 3\right.$, $\mathrm{p}<0.05$ ). When oral polio vaccine doses were analysed in a similar fashion, 106 children were documented to have received three doses, whereas parents had recalled it in only 86; this difference is highly significant $\left(\chi^{2}=13.9\right.$, $\mathrm{p}<0.001)$. To test the hypothesis that mothers of younger children would more accurately recall immunisations than mothers of older children, we carried out the same comparisons for the 69 children aged 12 months or less. In this group, 64 were documented to have received all required injections of triple antigen or combined diphtheria-tetanus, compared with parental recall in 62; this was not significant. When oral polio vaccine doses were analysed, however, a significant difference was still found between the 64 children documented to have received all required doses and the 54 initially said to have received all required doses $\left(\chi^{2}=4 \cdot 7\right.$, $\mathbf{p}<0.05$ ). There was no difference between documented and recalled data for the measlesmumps/measles-mumps-rubella and 18 month booster vaccinations.

INPATIENT SURVEY

Mothers of 204 children in hospital were inter- 
Table 1 Providers of immunisations to 204 inpatients according to where patients lived

\begin{tabular}{|c|c|c|c|c|c|c|}
\hline & \multirow{2}{*}{$\begin{array}{l}\text { Total } \\
\text { No }\end{array}$} & \multicolumn{5}{|c|}{ No (\%) of inpatients immunised by various providers } \\
\hline & & $\begin{array}{l}\text { Private doctor } \\
\text { only }\end{array}$ & $\begin{array}{l}\text { Local council } \\
\text { only }\end{array}$ & $\begin{array}{l}\text { Department of } \\
\text { Health only }\end{array}$ & $\begin{array}{l}\text { More than } \\
\text { one }\end{array}$ & None \\
\hline $\begin{array}{l}\text { Sydney } \\
\text { Elsewhere }\end{array}$ & $\begin{array}{r}160 \\
44\end{array}$ & $\begin{array}{r}108(68) \\
28(65)\end{array}$ & $\begin{array}{r}11(7) \\
1(2)\end{array}$ & $\begin{array}{r}15(9) \\
9(20)\end{array}$ & $\begin{array}{r}25(16) \\
4(9)\end{array}$ & $\begin{array}{l}1(0 \cdot 6) \\
2(5)\end{array}$ \\
\hline Total & $204(100)$ & $136(67)$ & $12(6)$ & $22(11)$ & $29(14)$ & $3(1)$ \\
\hline
\end{tabular}

viewed and immunisation data verified for all of them. There were $87(43 \%)$ girls and 117 boys, mean age 11.7 months. Of the 204 children, 159 $(78 \%)$ had received all the required first year doses of triple antigen, and of the 33 children old enough to have received the 18 month booster dose, 15 had received this dose as triple antigen, and three as combined diphtheriatetanus. Thus $144(71 \%)$ were appropriately immunised for age with triple antigen, and an additional $20(9 \%)$ had received some doses of combined diphtheria-tetanus instead of triple antigen. One hundred and seventy six (86\%) children had received the correct number of oral polio vaccine doses, and $48(81 \%)$ of the 59 children aged 16 months or older had received measles-mumps/measles-mumps-rubella. Overall, only 135 of the 204 children (66\%) had complied fully with the recommended schedule.

COMPARISON OF INPATIENTS WITH OUTPATIENTS One hundred forty four of 204 inpatients (71\%) had received all triple antigen doses for age compared with 93 of 111 outpatients $(84 \%)$. This difference is significant $\left(\chi^{2}=6 \cdot 0, p<0 \cdot 02\right)$. In addition, 176 inpatients $(86 \%)$ had received all oral polio vaccine doses for age, compared with 106 outpatients $(95 \%)$. This difference is significant $\left(\chi^{2}=5 \cdot 6, p<0 \cdot 02\right)$. The compliance with measles-mumps immunisation in the two groups was similar $\left(\chi^{2}=0 \cdot 0, p>0.95\right)$.

\section{USE OF THE PERSONAL HEALTH RECORD}

When 24 of the 204 children either born outside New South Wales and the Australian Capital Territory, or before the introduction of the personal health record, were excluded from the analysis, $176(98 \%)$ of a possible 180 children had a personal health record; in the remainder the mothers had not been given them. Many parents, however, did not bring the personal health record into hospital at the time of admission, so that the personal health record was available for only $46 \%$ of children. Of 88 children admitted urgently (the casualty department, doctor's rooms, or interhospital transfer) only 30 (34\%) had their personal health record on admission, compared with 51 of 87 children (59\%) admitted electively $\left(\chi^{2}=9 \cdot 6, p<0 \cdot 01\right)$.

\section{PROVIDERS OF IMMUNISATIONS}

For analysis of usage patterns, the 204 children were divided into two groups according to where they lived: 'Sydney' (that is, those residing in central, eastern, northern, southern, western or south western health areas) and
Table 2 Accuracy of documentation of inpatients immunisation state in medical records when compared with immunisation records held by parents or providers of immunisations

\begin{tabular}{lll}
\hline $\begin{array}{l}\text { Accuracy of hospital } \\
\text { medical record }\end{array}$ & $\begin{array}{l}\text { No of patients } \\
\text { with complete } \\
\text { immunisations } \\
\text { verified }\end{array}$ & $\begin{array}{l}\text { No of patients } \\
\text { with incomplete } \\
\text { immunisations verified }\end{array}$ \\
\hline Correct:detailed & 58 & 26 \\
Correct:abbreviated & 65 & 6 \\
Incorrect & 5 & 14 \\
Undocumented & 27 & 3 \\
\hline Total & 155 & 49 \\
\hline
\end{tabular}

'elsewhere'. Immunisation providers were grouped for purposes of analysis into: 'private doctors' (general practitioners, medical practices, and paediatricians), 'local council', and 'Department of Health facilities' (comprising hospital immunisation clinics and early childhood centres) (table 1). There were 160 children living in 'Sydney' and 44 living 'elsewhere'. Most used private doctors exclusively for their immunisations, and a relatively small number used only local council clinics. When the users of multiple services were taken into account, private doctors were used for some or all immunisations by 131 Sydney residents $(82 \%)$, and by 31 of those living elsewhere $(70 \%)$. Similarly, local councils were used for some or all immunisations by 30 Sydney residents (19\%) and by four of those living elsewhere (9\%).

\section{ACCURACY OF MEDICAL NOTES}

The adequacy of documentation of immunisations in the children's medical notes compared with other records is shown in table 2 . Overall, documentation of immunisations was correct in 155 medical records $(76 \%)$, and incorrect or absent in $49(24 \%)$. Immunisation state was incorrect or undocumented in $32(19 \%)$ of the 155 medical notes of the children who were appropriately immunised and in 17 of 49 (35\%) of those incompletely immunised.

\section{Discussion}

These data show that the population of young children attending a children's hospital had a level of immunisation uptake lower than the $90-95 \%$ required for herd immunity to prevail in the general child population. ${ }^{16} 17$ The casualty and outpatients survey showed vaccine uptakes of $79 \%$ for measles-mumps, $90 \%$ for first year triple antigen, and $95 \%$ for oral polio vaccine. These data are difficult to compare with other studies because of differences in the populations surveyed and in other methods used, but a similar survey of children in casualty 
with verification of records conducted in western Sydney in 1980 reported $94 \%$ compliance with first year triple antigen and oral polio vaccine vaccinations. ${ }^{18}$

The casualty survey also emphasised several difficulties found in assessing immunisation reliably in this age group. There was a high incidence of mobility: $19 \%$ of families could not be contacted six to nine months after the survey forms were first completed. Basser, in an immunisation survey conducted in the southern metropolitan region of Sydney, found that roughly $13 \%$ of families with 18 month old children moved house annually. ${ }^{19}$ It may be suggested that the rates of immunisation reported in the casualty survey were falsely increased because mobile families with lower compliance could not be contacted, and thus were removed from the final analysis. This selection process did not occur during the inpatient survey. In the same study Basser found that children of mobile families had an $88 \%$ compliance with the 18 month booster vaccination, compared with $92 \%$ for children from families that had not moved house, so that this factor alone is unlikely to explain the difference in immunisation compliance between our inpatient and outpatient populations. ${ }^{19}$

A further difficulty concerns the accuracy of collected data when it is based on the parents' recollection, a problem previously pointed out by Menser et al. ${ }^{12}$ Analysis of the casualty survey showed that there was a significant difference between the child's immunisation state as recalled by the mother and that documented in written records. This applied to doses received during the first year of life, and inaccuracy was particularly noted in the mothers' recollections that fewer oral polio vaccine doses had been given than was actually so.

The inpatient survey showed inadequate compliance with all scheduled immunisations among children in hospital. Of this population, $86 \%$ were appropriately immunised for age with oral polio vaccine, $81 \%$ with measles-mumps, and $71 \%$ with triple antigen. Only $66 \%$ were fully immunisation for age in accordance with the schedule. These results are in direct contrast to those of recent population based studies of children of similar age. Two year old children born in the Penrith and Hawkesbury areas had uptakes of triple antigen and oral polio vaccine of $94 \%$, and of measles-mumps vaccine of $95 \%,{ }^{20}$ and $92 \%$ of children aged $8-11$ months born in Camden were fully immunised with triple antigen and oral polio vaccine. ${ }^{21}$ In neither of these studies, however, were data verified against reliable records. On the other hand, the present study may be compared with a report from a children's hospital in the United States, in which inpatient medical records were examined retrospectively to determine the immunisation state of children in hospital as recorded by the junior medical staff. Of the 85 records in which it was noted, $66(78 \%)$ reported that the children were fully immunised for age. ${ }^{22}$

The current study showed a high degree of inaccuracy in the medical documentation of immunisation in the notes of children in hospital. In $24 \%$ of all records the immunisations were either wrongly recorded, or not recorded at all. Moreover, this figure rose to $35 \%$ when only the records of children known to have incomplete immunisations were considered. Thus in the population studied it would not have been possible for medical staff to attempt to correct immunisation defects in one third of children, as this portion of the group would have remained unidentified. In comparison, the retrospective study from the United States found that in $19 \%$ of medical notes there was no record of immunisation. ${ }^{22}$

Ideally, the admission to hospital of a young child should give an opportunity to medical staff to determine accurately the child's immunisations, and to make a plan to correct any inadequacies, as most of these children are unlikely to have specific medical contraindications to immunisation. ${ }^{22}$ Such a plan might take the form of immunisation in hospital before discharge, referral to an immunisation clinic, or an annotation in the discharge summary requesting the family doctor to deal with the problem. The components of the required infrastructure are available; with few exceptions, every child admitted to hospital had a personal health record available, but it was brought into hospital in fewer than half of all admissions. Parents and providers of health care need to be educated regarding its optimal use. Parents must be reminded to take the personal health record to every health related contact, and to take it with the child at each admission to hospital. Health providers in the community must be strongly encouraged to make an entry in the personal health record at each of the child's visits. Finally, hospital staff looking after the child need to be educated to ask to see the personal health record at the time of the child's admission, and, if the personal health record indicates a need, to make a plan for the child's further immunisation. Only in this way can admission to hospital be used to detect and improve the current, poor immunisation records of young children in hospital.

I thank Dr M Gibbeson for his assistance in the design and conduct of the casualty and outpatients survey, and the clerical staff of the outpatients and casualty departments of The Prince of Wales Children's Hospital who distributed the questionnaires to the parents. I particularly wish to acknowledge the help of the parents. I particularly wish to acknowledge the help of
Mrs D Christie, who carried out many of the telephone interviews of parents and immunisation providers.

1 New South Wales Department of Health. Newsletter for medical practitioners. Sydney: New South Wales Department of Health, January, 1987.

2 New South Wales Department of Health. Measles-mumpsrubella vaccine introduction. Circular 89/69. Sydney: New South Wales Department of Health, 14 June, 1989.

3 Marwick C. Challenge for immunization programs: protect preschool, postschool generations. FैAMA 1988;260 $1675-6$.

4 Markowitz LE, Preblud SR, Orenstein WA, et al. Patterns of ransmission in measles outbreaks in the United States, 1985-1986. N Engl f Med 1989;320:75-81.

5 Centers for Disease Control. Measles outbreak-Chicago, 1989. $M M W R$ 1989;38:591-2.

6 Centers for Disease Control, Mumps - United States, 1985-1986. MMWR 1987;36:151-5.

7 Hutchins SS, Escolan J, Markowitz LE, et al. Measles outbreak among unvaccinated preschool-aged children: opportreak anites misced by tunities missed by health care providers
measles vaccine. Pediatrics $1989 ; 83: 369-74$.

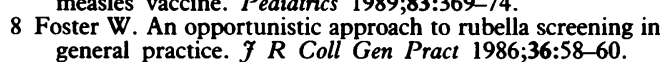

9 Robertson SE, Cochi SL, Bunn GA, Morse DL, Preblud SR. Preventing, Cochi SL, Bunn GA, Morse DL, Preblud SR. Preventing rubella: assessing missed opportunities for 
10 Hull D. Immunising children in hospital. Br Med f 1988;297: 755.

11 Fulginiti VA. Incomplete immunizations, hospitalization, and specialty care. Am f Dis Child 1988;142:704.

12 Menser MA, Collins E, Wu SW, Hudson J. Childhood immunization 1979. Disturbing statistics for metropolitan Sydney. Med f A A st 1980;2:131-4.

13 New South Wales Department of Health. Personal Health Record. Circular 87/259, 16 December, 1987.

14 World Health Organisation. Expanded programme on immunization. Evaluation of immunisation coverage. immunization. Evaluation of immunisation

15 Peter G, ed. Report of the Committee on Infectious Diseases (Red Book) 20th ed. Evanston: American Academy of Pediatrics, 1986:

16 Radford AJ. Immunisation patterns in Australia: the present situation and suggested future strategies. Community Health Stud 1982;4:228-38.

17 Anderson RM, May RM. Vaccination and herd immunity to infectious diseases. Nature 1985;318:323-9.

18 Christodoulou J, Clarke S, Buchanan N. Compliance with immunization programmes. Aust Paediatr f 1981;17:213-5.

19 Basser M. Immumization status and use of health services in the Southem. Immunization status and use of health services in the Southern Metropolitan Region, 1976. Rozelle: Health Commission of New South Wales, Southern Metropolitan Region, 1977

20 Bazeley PA. Immunisation status and service provision. Penrith: Castlereagh Area Health Board, 1988.

21 O'Flaherty SJ, Jandera E, Wall M. Source of immunization of infants. Med $\mathcal{F}$ Aust 1987;146:231.

22 Tifft CJ, Lederman HM. Immunization status of hospitalized preschool-age children. Am F Dis Child 1988;142:719-20.

\section{Forty years ago}

\section{Giardia lamblia infestation}

A study of the incidence of Giardia lamblia infestation was carried out at a residential nursery with accommodation for 30 mothers and 156 children under the age of 3 years. ${ }^{1}$ On admission cysts of giardia were found in $27 \%$ of the children over the age of 1 year and the incidence was higher in those who had previously been in a nursery than in those who had not. Stools were loose in $8 \%$ of children on admission, but of those who had been resident for three months or more $25 \%$ had loose stools and $80 \%$ were positive for giardia. Only $4 \%$ of the mothers and nurses were positive.

Children with giardia who were treated with mepacrine showed a marked decrease in the incidence of loose stools and a greater gain in weight than untreated controls. Giardia cysts were completely eliminated from the stools after a few days of treatment. In a sample of 14 infants with giardia the faecal fat excretion on a normal fat intake was not above normal.

\section{Tonsillectomy}

In the immediate postwar years some 200000 tonsillectomies a year were being performed in this country. ${ }^{2}$ In many hospitals this operation was the commonest reason for the admission of children to hospital.

In England and Wales in the three years preceding the war $16 \%$ of children in state schools had had their tonsils removed by the age of 13 , compared with $83 \%$ of boys of that age entering Eton. In Kent County Council schools the overall incidence of tonsillectomy was $16 \%$ but in the local districts it ranged from $1 \%$ in Deal to $42 \%$ in Tunbridge Wells.

The indications for tonsillectomy listed in textbooks at the time included every possible symptom arising from the upper respiratory tract as well as some more remote conditions such as rheumatic fever, asthma, glomerulonephritis, anorexia, and sleep disorders. Are we finally agreed on the indications for tonsillectomy 40 years later?

\section{Studies in neonates}

Part 4 of Drillien's series of studies of premature babies born at the Simpson Memorial Pavilion, Edinburgh in the 1940s included reports on breast feeding and neonatal infection. ${ }^{3}$

Of 100 premature babies $44 \%$ were fully breast fed for more than one month and $36 \%$ for more than three months. For mature control babies the comparable figures were $67 \%$ and $48 \%$. Some $24 \%$ of the premature babies weighed under $2000 \mathrm{~g}$ at birth and three quarters of these were never breast fed.

In the first 10 days of life the commonest infections were skin and eye infections due to Staphylococcus aureus, thrush, and gastroenteritis. The infection rate in relation to birth weight was: $31 \%$ under $3.5 \mathrm{lb}(1600 \mathrm{~g}), 14 \%$ between $3.5 \mathrm{lb}(1600 \mathrm{~g})$ and $4.5 \mathrm{lb}(2000 \mathrm{~g}), 10 \%$ between $4.5 \mathrm{lb}(2000 \mathrm{~g})$ and $5.5 \mathrm{lb}(2500 \mathrm{~g})$, and $6 \%$ in those over $5.5 \mathrm{lb}(2500 \mathrm{~g})$.

In a maternity hospital in Belfast, where the average stay for mothers and babies in 1946 was 10.3 days, over $80 \%$ of neonatal infections were due to $S$ aureus. ${ }^{4}$

At the Queen Elizabeth Hospital for Children, London, cultures from 11 of 15 neonates admitted with septicaemia in 1946 grew $S$ aureus. ${ }^{5}$ One baby had septic arthritis and two had osteomyelitis of the maxilla; seven died.

1 Brown EH. Giardia lamblia. The incidence and results of infestion infestation of children

2 Glover JA. The paediatric approach to tonsillectomy. Arch Dis Child 1948;23:1-6.

3 Drillien CM. Studies in prematurity. Part 4. Arch Dis Child 1948;23:69-83.

4 Frazer MJL. A study of neonatal infections in the nursery of a maternity hospital. Arch Dis Child 1948;23:107-13.

5 Todd RM. Septicaemia of the newborn. Arch Dis Child 1948;23:102-6.

ADM JACKSON 